\title{
Introduction to Special Issue of Radiology and Imaging of Cancer
}

\author{
Roberta Fusco $₫$, Vincenza Granata * and Antonella Petrillo \\ Radiology Division, Istituto Nazionale Tumori_-IRCCS—Fondazione G. Pascale, Via Mariano Semmola, \\ 80131 Naples, Italy; r.fusco@istitutotumori.na.it (R.F.); a.petrillo@istitutotumori.na.it (A.P.) \\ * Correspondence: v.granata@istitutotumori.na.it; Tel.: +39-(08)-1590714; Fax: +39-08-1590-3825
}

Received: 11 September 2020; Accepted: 15 September 2020; Published: 18 September 2020

Keywords: MRI; CT; PET; oncology; computed analysis

The increase in knowledge in oncology and the possibility of creating personalized medicine by selecting a more appropriate therapy related to the different tumor subtypes, as well as the management of patients with cancer within a multidisciplinary team has improved the clinical outcomes [1].

The characteristics involved are a more appropriate surveillance for the patient at risk to obtain an early diagnosis of the disease, an improvement in the efficacy of therapies based on better patient selection [1,2] and, thanks to a more strategic approach, the possibility of identifying responders or non-responders to therapies as soon as possible, not least the possibility of selecting different treatments related to genomic data. In fact, it has been shown that genomic markers such as microRNA expression are associated with the response to treatment, metastatic spread and prognosis that could offer personalized and precision medicine. In this scenario, the radiologist's rule has profoundly changed.

Medical imaging comprises a huge number of imaging techniques, and multiple biomedical imaging techniques are used in all phases of cancer management because they are able to provide morphological and functional data [2-19]. In addition, image-guided invasive therapy has the promise to improve outcomes and reduce collateral effects compared to systemic or surgical treatment $[20,21]$. Hybrid imaging techniques are able to supply complementary information for improved staging and therapy planning [22-24]. Early detection of cancer through screening based on imaging is probably the major contributor to a reduction in mortality for certain cancers [25]. Nowadays, imaging can also characterize several lesions and predict their histopathological features and can predict tumor behavior and prognosis [26].

Imaging diagnosis can be assisted by computed analysis. At present, new parameters can be evaluated using computer-assisted imaging analysis that would be not visible during standard radiological evaluation and reporting and can be used for oncologic evaluations and response to therapy and could cover new significant roles, such as the evaluation of tumor aggressiveness and prognostic prediction.

Recent technological advances in medical imaging, especially in the field of artificial intelligence for the processing of large quantities of iconographic data from different imaging modalities, hold promise in addressing clinical challenges in cancer detection, assessment of treatment response, and monitoring disease progression $[10,12,13,27-29]$.

In this context three different broad approaches can be identified, whose tentative definitions, although continuously updated, can be currently outlined as radiomics, machine learning and deep learning.

Radiomics includes feature extraction from clinical images; these features are related to tumor size, shape, intensity, and texture, collectively providing comprehensive tumor characterization (the so-called radiomics signature of the tumor) [30,31]. The use of imaging data from routine clinical 
work-up has tremendous potential in improving cancer care by heightening understanding of tumor biology and aiding in the implementation of precision medicine. As a noninvasive method of assessing the tumor and its microenvironment in their entirety, radiomics allows the evaluation and monitoring of tumor characteristics such as temporal and spatial heterogeneity [32].

Machine learning (ML) is a branch of artificial intelligence centered on algorithms which do not need explicit prior programming to function but automatically learn from available data, creating decision models to complete tasks. ML-based tools have been proposed for applications in oncology for oncological risk assessment, automated segmentation, lesion detection, characterization, grading and staging, prediction of prognosis and therapy response [33].

Deep learning is a renewed area of research that deals with development of deep artificial neural networks that were inspired by biological neural networks in our brain. In radiology, deep neural networks, like biological neural networks, attempt to learn an intrinsic representation of the radiological data. Deep learning has become an active area of research in the field of computer-assisted clinical and radiological decision support in recent years, with some excellent initial results that have been recently surveyed [27,34].

Technological developments will increase imaging speed to match that of physiological processes. Targeted imaging and therapeutic agents will be developed in tandem through close collaboration between academia and biotechnology, information technology and pharmaceutical industries.

The aim of this Special Issue is to present new challenges in cancer imaging, including the potential applications of radiomics and artificial intelligence in several malignancies.

Funding: This research received no external funding.

Conflicts of Interest: The authors declare no conflict of interest.

\section{References}

1. Beyer, T.; Bidaut, L.; Dickson, J.; Kachelriess, M.; Kiessling, F.; Leitgeb, R.; Ma, J.; Sundar, L.K.S.; Theek, B.; Mawlawi, O. What scans we will read: Imaging instrumentation trends in clinical oncology. Cancer Imaging 2020, 20, 1-38. [CrossRef]

2. Vaidya, T.; Agrawal, A.; Mahajan, A.; Thakur, M.H.; Mahajan, A.; Aggarwal, A. The Continuing Evolution of Molecular Functional Imaging in Clinical Oncology: The Road to Precision Medicine and Radiogenomics (Part II). Mol. Diagn. Ther. 2018, 23, 27-51. [CrossRef] [PubMed]

3. Mainenti, P.; Stanzione, A.; Guarino, S.; Romeo, V.; Ugga, L.; Romano, F.; Storto, G.; Maurea, S.; Brunetti, A. Colorectal cancer: Parametric evaluation of morphological, functional and molecular tomographic imaging. World J. Gastroenterol. 2019, 25, 5233-5256. [CrossRef] [PubMed]

4. Ronot, M.; Clift, A.K.; Vilgrain, V.; Frilling, A. Functional imaging in liver tumours. J. Hepatol. 2016, 65, 1017-1030. [CrossRef] [PubMed]

5. Vaidya, T.; Agrawal, A.; Mahajan, S.; Thakur, M.H.; Mahajan, A. The Continuing Evolution of Molecular Functional Imaging in Clinical Oncology: The Road to Precision Medicine and Radiogenomics (Part I). Mol. Diagn. Ther. 2018, 23, 1-26. [CrossRef] [PubMed]

6. Granata, V.; Fusco, R.; Filice, S.; Catalano, O.; Piccirillo, M.; Palaia, R.; Izzo, F.; Petrillo, M. The current role and future prospectives of functional parameters by diffusion weighted imaging in the assessment of histologic grade of HCC. Infect. Agents Cancer 2018, 13, 23. [CrossRef]

7. Granata, V.; Fusco, R.; Reginelli, A.; DelRio, P.; Selvaggi, F.; Grassi, R.; Izzo, F.; Petrillo, A. Diffusion kurtosis imaging in patients with locally advanced rectal cancer: Current status and future perspectives. J. Int. Med. Res. 2019, 47, 2351-2360. [CrossRef]

8. Fusco, R.; Granata, V.; Rega, D.; Russo, C.; Pace, U.; Pecori, B.; Tatangelo, F.; Botti, G.; Izzo, F.; Cascella, M.; et al. Morphological and functional features prognostic factor of magnetic resonance imaging in locally advanced rectal cancer. Acta Radiol. 2018. [CrossRef]

9. Petrillo, M.; Catalano, O.; Fusco, R.; Filice, S.; Vallone, P.; Setola, S.; Granata, V.; Raiano, C.; Avino, F.; Di Bonito, M.; et al. Optical imaging of the breast: Evaluation of deoxyhemoglobin concentration alteration in 166 patients with suspicious breast lesions. Eur. Radiol. Exp. 2018, 2, 8. [CrossRef] 
10. Petrillo, A.; Fusco, R.; Petrillo, M.; Granata, V.; Sansone, M.; Avallone, A.; DelRio, P.; Pecori, B.; Tatangelo, F.; Ciliberto, G. Standardized Index of Shape (SIS): A quantitative DCE-MRI parameter to discriminate responders by non-responders after neoadjuvant therapy in LARC. Eur. Radiol. 2015, 25, 1935-1945. [CrossRef]

11. Fusco, R.; Sansone, M.; Granata, V.; Di Bonito, M.; Avino, F.; Catalano, O.; Botti, G.; Petrillo, M. Use of Quantitative Morphological and Functional Features for Assessment of Axillary Lymph Node in Breast Dynamic Contrast-Enhanced Magnetic Resonance Imaging. BioMed Res. Int. 2018, 2018, 1-8. [CrossRef] [PubMed]

12. Petrillo, A.; Fusco, R.; Petrillo, M.; Granata, V.; Bianco, F.; Di Marzo, M.; DelRio, P.; Tatangelo, F.; Botti, G.; Pecori, B.; et al. DCE-MRI time-intensity curve visual inspection to assess pathological response after neoadjuvant therapy in locally advanced rectal cancer. Jpn. J. Radiol. 2018, 36, 611-621. [CrossRef] [PubMed]

13. Petrillo, A.; Fusco, R.; Granata, V.; Filice, S.; Sansone, M.; Rega, D.; DelRio, P.; Bianco, F.; Romano, G.M.; Tatangelo, F; et al. Assessing response to neo-adjuvant therapy in locally advanced rectal cancer using Intra-voxel Incoherent Motion modelling by DWI data and Standardized Index of Shape from DCE-MRI. Ther. Adv. Med. Oncol. 2018, 10. [CrossRef]

14. Patella, F.; Franceschelli, G.; Petrillo, M.; Sansone, M.; Fusco, R.; Pesapane, F.; Pompili, G.; Carrafiello, G.; Saibene, A.M.; Moneghini, L.; et al. A multiparametric analysis combining DCE-MRI- and IVIM -derived parameters to improve differentiation of parotid tumors: A pilot study. Futur. Oncol. 2018, 14, 2893-2903. [CrossRef] [PubMed]

15. Granata, V.; Fusco, R.; Maio, F.; Avallone, A.; Nasti, G.; Palaia, R.; Albino, V.; Grassi, R.; Izzo, F.; Petrillo, A. Qualitative assessment of EOB-GD-DTPA and Gd-BT-DO3A MR contrast studies in HCC patients and colorectal liver metastases. Infect. Agents Cancer 2019, 14, 1-9. [CrossRef]

16. Granata, V.; Fusco, R.; Setola, S.V.; Picone, C.; Vallone, P.; Belli, A.; Incollingo, P.; Albino, V.; Tatangelo, F.; Izzo, F.; et al. Microvascular invasion and grading in hepatocellular carcinoma: Correlation with major and ancillary features according to LIRADS. Abdom. Radiol. 2019, 44, 2788-2800. [CrossRef]

17. Granata, V.; Fusco, R.; Setola, S.V.; Palaia, R.; Albino, V.; Piccirillo, M.; Grimm, R.; Petrillo, A.; Izzo, F. Diffusion kurtosis imaging and conventional diffusion weighted imaging to assess electrochemotherapy response in locally advanced pancreatic cancer. Radiol. Oncol. 2019, 53, 15-24. [CrossRef]

18. Petrillo, A.; Fusco, R.; Vallone, P.; Filice, S.; Granata, V.; Petrosino, T.; Rubulotta, M.R.; Setola, S.V.; Raso, M.M.; Maio, F.; et al. Digital breast tomosynthesis and contrast-enhanced dual-energy digital mammography alone and in combination compared to 2D digital synthetized mammography and MR imaging in breast cancer detection and classification. Breast J. 2019, 26, 860-872. [CrossRef]

19. Fusco, R.; Sansone, M.; Granata, V.; Grimm, R.; Pace, U.; DelRio, P.; Tatangelo, F.; Botti, G.; Avallone, A.; Pecori, B.; et al. Diffusion and perfusion MR parameters to assess preoperative short-course radiotherapy response in locally advanced rectal cancer: A comparative explorative study among Standardized Index of Shape by DCE-MRI, intravoxel incoherent motion- and diffusion kurtosis imaging-derived parameters. Abdom. Radiol. 2018, 44, 3683-3700. [CrossRef]

20. Degrauwe, N.; Hocquelet, A.; Digklia, A.; Schaefer, N.; Denys, A.; Duran, R. Theranostics in Interventional Oncology: Versatile Carriers for Diagnosis and Targeted Image-Guided Minimally Invasive Procedures. Front. Pharmacol. 2019, 10. [CrossRef]

21. Ghai, S.; Trachtenberg, J. MRI-guided biopsies and minimally invasive therapy for prostate cancer. Indian J. Urol. 2015, 31, 209-216. [CrossRef] [PubMed]

22. Jha, P.; Bijan, B.; Melendres, G.; Shelton, D.K. Hybrid Imaging for Pancreatic Malignancy. Clin. Nucl. Med. 2015, 40, 206-213. [CrossRef]

23. Bhure, U.; Roos, J.E.; Strobel, K. Osteoid osteoma: Multimodality imaging with focus on hybrid imaging. Eur. J. Nucl. Med. Mol. Imaging 2018, 46, 1019-1036. [CrossRef] [PubMed]

24. Ahmadzadehfar, H.; Muckle, M.; Essler, M.; Biersack, H.; Von Mallek, D. SPEC/CT: Vorteile und Indikationen der Hybridbildgebung. DMW Dtsch. Med. Wochenschr. 2015, 140, 434-438. [CrossRef] [PubMed]

25. Schiffman, J.D.; Fisher, P.; Gibbs, P. Early Detection of Cancer: Past, Present, and Future. Am. Soc. Clin. Oncol. Educ. Book 2015, 35, 57-65. [CrossRef] [PubMed]

26. Granata, V.; Fusco, R.; Risi, C.; Ottaiano, A.; Avallone, A.; De Stefano, A.; Grimm, R.; Grassi, R.; Brunese, L.; Izzo, F; et al. Diffusion-Weighted MRI and Diffusion Kurtosis Imaging to Detect RAS Mutation in Colorectal Liver Metastasis. Cancers 2020, 12, E2420. [CrossRef] 
27. Piantadosi, G.; Sansone, M.; Fusco, R.; Sansone, C. Multi-planar 3D breast segmentation in MRI via deep convolutional neural networks. Artif. Intell. Med. 2019, 103, 101781. [CrossRef]

28. Fusco, R.; Sansone, M.; Filice, S.; Carone, G.; Amato, D.M.; Sansone, C.; Petrillo, A. Pattern Recognition Approaches for Breast Cancer DCE-MRI Classification: A Systematic Review. J. Med. Boil. Eng. 2016, 36, 449-459. [CrossRef]

29. Fusco, R.; Di Marzo, M.; Sansone, C.; Sansone, M.; Petrillo, M. Breast DCE-MRI: Lesion classification using dynamic and morphological features by means of a multiple classifier system. Eur. Radiol. Exp. 2017, 1, 10. [CrossRef]

30. Fusco, R.; Granata, V.; Maio, F.; Sansone, M.; Petrillo, A. Textural radiomic features and time-intensity curve data analysis by dynamic contrast-enhanced MRI for early prediction of breast cancer therapy response: Preliminary data. Eur. Radiol. Exp. 2020, 4, 1-7. [CrossRef]

31. Avanzo, M.; Stancanello, J.; El Naqa, I. Beyond imaging: The promise of radiomics. Phys. Medica 2017, 38, 122-139. [CrossRef] [PubMed]

32. Limkin, E.J.C.; Sun, R.; Dercle, L.; Zacharaki, E.I.; Robert, C.; Reuzé, S.; Schernberg, A.; Paragios, N.; Deutsch, E.; Ferté, C. Promises and challenges for the implementation of computational medical imaging (radiomics) in oncology. Ann. Oncol. 2017, 28, 1191-1206. [CrossRef] [PubMed]

33. Cuocolo, R.; Caruso, M.; Perillo, T.; Ugga, L.; Petretta, M. Machine Learning in oncology: A clinical appraisal. Cancer Lett. 2020, 481, 55-62. [CrossRef] [PubMed]

34. Parekh, V.S.; Jacobs, M.A. Deep learning and radiomics in precision medicine. Expert Rev. Precis. Med. Drug Dev. 2019, 4, 59-72. [CrossRef] [PubMed]

(C) 2020 by the authors. Licensee MDPI, Basel, Switzerland. This article is an open access article distributed under the terms and conditions of the Creative Commons Attribution (CC BY) license (http://creativecommons.org/licenses/by/4.0/). 